\title{
Receiving voluntary family planning services has no relationship with the paradoxical situation of high use of contraceptives and abortion in Vietnam: a cross-sectional study
}

\author{
Phuong Hong Nguyen ${ }^{1 *+}$ and Meiwita P Budiharsana ${ }^{2 \dagger}$
}

\begin{abstract}
Background: Vietnam shows a paradoxical situation where high contraceptive prevalence goes together with high abortion rates. This study examined the associations between self-reports of having received voluntary family planning (VFP) services and induced abortions.

Methods: A cross sectional survey was conducted in Thai Nguyen province, covering a total of 1281 women. Data were derived from a sample of 935 married women aged 18-49 years who were ever-users (93.5\%) and current users of contraceptives (84\%), and had completed birth histories. The dependent variables were the likelihood of having an induced abortion and repeated (two or more) induced abortions. The main independent variable was having received the three VFP dimensions (counselling, broader information, and access to availability). The association was examined using multivariate logistic regressions, taking into account women's socio-demographic characteristics.

Results: The overall induced abortion percentage was 19.4 per 100 pregnancies. None of the three VFP dimensions was significantly associated with the odds of having an induced abortion or having repeated induced abortions. Mother's age of 35 or older, having more than three living children, and ever used female contraception methods significantly doubled or more the odds of having an induced abortion and significantly tripled the odds of having repeated abortions.

Conclusions: Results indicate that women receiving VFP services were not less likely to have induced abortions. The provision of family planning counselling, information on contraceptive method mix, and management skills to ensure availability, are in need of reinforcement in a new set of policy and program strategies in the future.
\end{abstract}

Keywords: Voluntary family planning (VFP), Contraceptive use, Induced abortion, Counselling, Access, Vietnam

\section{Background}

High induced abortion rates (over 1,000,000 abortion per year) and high prevalence of contraceptive use (79\%) created a paradoxical situation in Vietnam [1-4]. Around 1999, the country's family planning services included the three Voluntary Family Planning (VFP) dimensions: family planning counselling; broader information on

\footnotetext{
* Correspondence: nhphuong68@yahoo.com

${ }^{\dagger}$ Equal contributors

'Department of Scientific Research and International Relationship, Thai Nguyen University of Medicine and Pharmacy, Thai Nguyen, Vietnam Full list of author information is available at the end of the article
}

contraceptive methods that lead to informed voluntary choice; and access to and availability of preferred method(s), all of which encourage contraceptive users to continue using the method and therefore should reduce the need for induced abortions [5]

The family planning program in Vietnam has gone through a long journey. It began as an unofficial program in 1963, was officially instituted through the Council of Ministers Decree No 162-HDBT/1988 and was further reinforced by Resolution 4/1993. The emphasis was solely on a two-child per couple policy with 3 to 5 years of spacing [6]. The target population defined by

\section{Ciomed Central}


policy makers in the 1980s consisted entirely of married women. The program did not encourage unmarried women to buy and use either condoms or contraceptive pills. Consequently, there were no family planning services, or even information, for young women who were interested in understanding how to use oral pills and their immediate and long-term side-effects. Women were also uncomfortable buying condoms, because the surrounding society perceived doing so as a sign of a casual approach to sexual relations. This situation explains why there was such a high rate of reliance on traditional methods until now, although women knew that traditional methods are less effective in preventing unwanted pregnancies [7]. Family planning policy makers at that time believed that the intrauterine device (IUD) was the most effective way to meet the official fertility targets of a two-children-per-couple policy with 3 to 5 years of spacing. From the beginning, the family planning program in Vietnam relied heavily on IUDs. Strong campaigns to promote exclusive IUD use were conducted in the 1980s, followed in the mid-1990s by campaigns to promote female (tubal) sterilization [8]. Consequently, for decades, only one modern method, the IUD, predominated in Vietnam's contraceptive method mix. Other modern methods such as pills, injectables and condoms have been given less attention [9].

During that era, the 6-year pre-service training for medical doctors and 3-year pre-service training for nurses/ midwives/physician assistants did not include academic curricula related to the VFP dimensions. An introductory family planning course of less than 20 hours was given to sixth-year medical students only. However, if a physician or nurse/ midwife/ physician assistant wanted to provide abortion services, they could undergo a 2-month certification course at the provincial reproductive health center after graduation. This certification course was an in-service training with similar course content for physicians and nurses/midwives/ physician assistants [10].

Abortion services are legal in Vietnam, if provided through public or qualified private facilities, under a Decree that enabled privatization of the health sector in 1989 [10]. However, it is suspected that many abortion services were delivered without $\mathrm{MOH}$ certification because the provider's qualifications, equipment, and facility sanitation did not meet standard medical requirements 10]. Between 1982 and 1994, induced abortions rose six-fold, leading Vietnam to be a country that has one of the highest abortion rates in the world (with over $1,000,000$ abortions per year, or an average of 2.5 induced abortions in a woman's reproductive life) $[10,11]$. Each year, approximately 500,000 abortions were reported in the public sector, and another one-third to one-half as many were performed in small health clinics which are suspected of contributing to high women's death rates [4,10,12]. Limited contraceptive choices, improper use of modern contraceptives and reliance on withdrawal or periodic abstinence contributed to this situation $[1,2,13]$. Findings from a joint study led by the Ministry of Health/World Health Organization in 1999 concluded that 'lack of counselling and comprehensive information on available contraceptive method mix' were associated with the high abortion practices [14]. A multi-donor reproductive health project built a network of in-service trainings (clinical and management) for almost 2,000 health facilities at the national, provincial, district, and commune level in 17 provinces between 1994 and 2009, involving a total budget over 20 million dollars. The three dimensions of VFP - provision of family planning counselling, information on contraceptive method mix, and management skills to ensure availability - were included and adopted in the national standards and guidelines for counselling in regard to family planning and safe abortion [15].

The purpose of this study is to examine the associations between receipt of VFP services and seeking induced abortions and repeated abortions.

\section{Methods}

\section{Study design and sampling description}

A cross-sectional survey was conducted between February and May 2011 in four of the nine districts (which account for $52 \%$ of the province's total population) of Thai Nguyen province in northern Vietnam. These districts have high proportions of indigent and ethnic minority women. A representative sample of married women aged 18-49 years was selected from the 4 districts by a twostage cluster sampling technique. The first stage of sampling selected 40 communes as primary sampling units, with probability of inclusion proportional to the size of the population in each district. The second stage selected 40 individual respondents in each commune by use of systematic sampling. Respondents were informed about the purpose of the study, and written informed consent was obtained from all respondents. All interviews were conducted in private to ensure confidentiality and privacy. Interviewers were trained to protect confidentiality including the identity of every respondent as well as the secrecy of all recorded information. Interviewers were trained medical doctors undergoing specialization to become obstetricians, with sufficient technical ability to distinguish induced abortions, stillbirths, and miscarriages. Each woman was assigned a respondent code so that her identifying information was known only by the lead investigator; no one else was authorized to see the coded list. All completed questionnaires were stored in locked file cabinets so that only 
limited research personnel had access to the raw data. This cross-sectional survey received ethical approval from the Institutional Review Board of the Institute of Social and Medicine Studies in Vietnam.

\section{Operational definitions of variables}

The main dependent variables consisted of the probability of ever having induced abortion or ever having repeated (two or more) induced abortions. The structure of the data set did not allow computation of induced abortion ratio by birth order, but allowed the calculation of abortion percentages by mother's age at the time of an induced abortion. A complete pregnancy history (total pregnancies) of each respondent was computed from the sum of: pregnancies ending in live births and still births (fetal deaths of at least 20 weeks' gestation), infant deaths (less than or equal to 1 year in age), child deaths (older than 1 year), abortions (medical and surgically induced abortions), and miscarriages (spontaneous abortions regardless of gestation period). Total stated abortions divided by total calculated pregnancies generated the maternal age-specific induced abortion percentages, classified for women 18-24 years, 25-34 years, 35-49 years, and for all ages.

The main independent variable, Voluntary Family Planning (VFP), consisted of three dimensions: ever received family planning counselling; ever received information on contraceptive methods leading to voluntary choice; and perception of access or availability of the selected method(s). Counselling was related to ever receiving family planning counselling from a provider (public or private) during the last family planning visit. Information on family planning method(s) was measured by responses to five yes/no questions related to: receiving advice from a health or population worker; receiving information about a variety of methods; effectiveness of chosen method; side-effects and complications; and knowing what to do when side-effects or complications occurred. Access or availability was measured by responses to three questions related to the respondent's perceptions about the selected method: its availability; whether it had a reasonable price; and how easy it was to obtain and use. The Cronbach's alpha coefficient of internal consistency was not used because the individual scale items were set the same.

Other key independent variables:

(1) Combined total family planning 'ever-users' and 'current users' of contraception that was recategorized into two binary variables: use of femaleonly methods (yes = 1 and no $=0$ ); and use of couple methods (yes = 1 and no =0) [16]. Ever-users were women who said they had used at least one family planning method; and current users were women who said they currently use a family planning method to delay or avoid becoming pregnant. Female-only methods included oral pills, intrauterine devices (IUDs), injectables, implants, and female sterilization. Couple methods included male and female condoms, withdrawal, and periodic abstinence, all of which require a certain degree of support and cooperation from husbands/partners.

(2) Women's age at interview (categorized into 1824 years, 25-34 years, and 35-49 years);

(3) Number of living children (alive at the time of the survey, grouped as: 1, 2, and 3+);

(4) Ethnicity (Kinh majority and others: Tay, Nung, Dao, H'mong, Sa Chay, San Diu, and other minority groups);

(5) Wealth index that was constructed based on housing characteristics and household assets: housing quality (roof, wall, floor materials); standard services (water, electricity, type of fuel for cooking, type of toilet); fixed-assets (house, number of rooms, land ownership); durable assets and livestocks $[17,18]$; The wealth index was constructed using principle components analysis [19] and were then divided into quintiles.

(6) Other control variables such as education, occupation, residence, sex of previous child.

\section{Statistical analyses}

Bivariate analysis was carried out to explore the differentials in induced abortions and ever receiving VFP dimensions, using the chi-square test. Logistic regression was used to re-examine the association between induced abortions as a dependent variable and the VFP dimensions, controlling for socio-demographic characteristics and taking into account design effects resulting from clustering at the level of the primary sampling unit. The results are presented in the form of odds ratios (ORs), with 95\% confidence intervals (95\% CIs). The analysis was conducted using Stata 11.

\section{Results}

\section{Sample characteristics}

Of the 1281 women who consented to take part and completed the survey, 935 women were married or living with a partner, were aged 18-49 years, and had completed birth history. High proportions of women were ever-users (93.5\%) and current users (84\%). Among ever-users, $45.7 \%$ had used couple methods and $73.2 \%$ had used female methods. Among current users, 43.3\% were using couple methods and $56.7 \%$ were using female only methods. The distribution of family planning methods by past and current users is shown in Figure 1, indicating that IUDs predominate modern methods, followed by condoms and pills. Other modern methods 


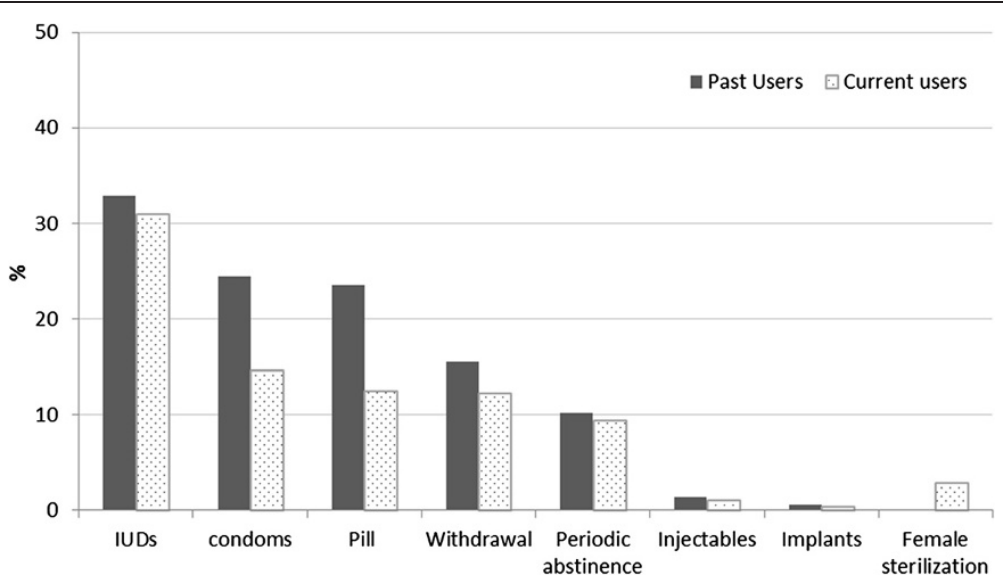

Figure 1 Distribution of various family planning methods, by past and current-users among women 18-49 years of age, Thai Nguyen, Vietnam, $2011(n=935)$.

such as injectables and implants remain less than $1 \%$. Only $14.6 \%$ of women stated they had received all three dimensions of VFP. About 43.9\% stated they had received counselling, $31.6 \%$ had received broader information to make an informed choice, and $37.6 \%$ had access to their preferred method.

There were 19.4 induced abortions per 100 pregnancies in the study population. Induced abortion percentage increased with maternal age. The lowest induced abortion percentage $(8.8 \%)$ was among women aged $18-$ 24 years, which increased to $13.8 \%$ among women aged 25-34 years, and reached a peak of $22.2 \%$ (about 2.5 times the rate of the youngest group) among women aged 35-49 years.

\section{Bivariate analyses}

Table 1 presents the results of bivariate analysis to explore the differentials in ever having zero, one, or two and more induced abortions and women's experience in ever receiving VFP (any one, any two or all three dimensions), and other maternal and socio-economic characteristics.

The experience of ever having induced abortions did not differ significantly between women who had ever and those who had never received family planning counseling; between women who had ever and those who had never received broader information on contraceptive methods; nor women who had access or those who had no access to their preferred method. Data did not allow an investigation into whether women contraceptive users who received VFP services were more likely to continue using contraceptives, in particular their preferred contraceptive methods. However, the number of women who discontinued the use of contraception was relatively small (95 out of 935).
The probability of having abortions significantly differed by woman's age at interview, place of residence, type of occupation, wealth, and number of living children; and also in regard to ever-used couple methods and ever-used female methods.

Ethnicity, education, and sex of previous child were not significantly associated with the probability of having induced abortions (one time or repeated).

\section{Multivariate logistic regression}

Table 2 presents results from multivariate logistic regression. None of three VFP dimensions (counseling, information, and access) was shown to be associated with the odds of having an induced abortion or the odds of having repeated abortions.

The odds of having an induced abortion more than doubled with an increase in women's age (at interview) category: the odds were 2.37 times greater among women aged 25-34, and almost 4 times greater among women aged 35-49 years, compared to women aged 18-24 years. Women aged 18-24 years showed no repeated abortions. But the odds of having repeated abortions (twice or more) among women aged 3549 years were 2.78 times greater than among women aged 18-34 years (18-24 and 25-34 years pooled).

Ethnicity was not significantly associated with the odds of having an induced abortion nor the odds of having repeated abortions among women of the majority Kinh ethnic group compared to minority women.

Working as a farmer was significantly associated with $43 \%$ lower odds of having an induced abortion and 36\% lower odds of having repeated abortions. Farmers accounted for $65 \%$ of the study's respondents. In addition, because farmers always need extra hands to help in the field, they did not completely comply with the government's two-children per couple policy. 
Table 1 Bivariate analysis between induced abortions and voluntary family planning dimensions and socio-demographic characteristics

\begin{tabular}{|c|c|c|c|c|}
\hline \multirow[b]{2}{*}{ Voluntary Family Planning dimensions } & \multicolumn{4}{|c|}{ Ever had induced abortions $(n=935)$} \\
\hline & 0 & 1 & $\geq 2$ & $P$-value \\
\hline Counselling & & & & 0.054 \\
\hline No & 61.3 & 25.5 & 13.2 & \\
\hline Yes & 68.8 & 21.0 & 10.2 & \\
\hline Information for making informed choice & & & & 0.371 \\
\hline No & 65.3 & 22.5 & 12.2 & \\
\hline Yes & 68.8 & 21.3 & 9.9 & \\
\hline Access/availability to selected method(s) & & & & 0.813 \\
\hline No & 64.0 & 24.2 & 11.8 & \\
\hline Yes & 65.8 & 22.4 & 11.9 & \\
\hline Counselling + information & & & & 0.083 \\
\hline No & 61.6 & 25.4 & 13.1 & \\
\hline Yes & 68.5 & 21.2 & 10.4 & \\
\hline All three components & & & & 0.105 \\
\hline No & 60.2 & 27.2 & 12.7 & \\
\hline Yes & 66.9 & 21.7 & 11.5 & \\
\hline Age at interview & & & & 0.000 \\
\hline $18-24$ & 89.9 & 10.1 & 0.0 & \\
\hline $25-34$ & 77.0 & 17.8 & 5.2 & \\
\hline $35-49$ & 56.5 & 26.6 & 16.9 & \\
\hline Place of residents & & & & 0.000 \\
\hline Rural & 70.1 & 21.4 & 8.5 & \\
\hline Urban & 59.7 & 23.4 & 16.9 & \\
\hline Ethnicity & & & & 0.052 \\
\hline Kinh & 68.9 & 22.8 & 8.3 & \\
\hline Others (ethnic minorities) & 65.3 & 21.8 & 13.0 & \\
\hline Education & & & & 0.706 \\
\hline Primary and secondary & 66.9 & 22.3 & 10.8 & \\
\hline High school and higher (college/university) & 66.1 & 21.6 & 10.3 & \\
\hline Occupation & & & & 0.002 \\
\hline Others & 60.1 & 25.9 & 14.1 & \\
\hline Farmers & 69.9 & 20.1 & 10.1 & \\
\hline Wealth index (quintiles) & & & & 0.001 \\
\hline Lowest & 74.3 & 18.5 & 7.2 & \\
\hline Second & 71.0 & 21.0 & 7.9 & \\
\hline Middle & 66.5 & 22.7 & 10.8 & \\
\hline Fourth & 62.5 & 23.7 & 13.8 & \\
\hline Highest & 57.7 & 24.4 & 17.9 & \\
\hline Number of living children & & & & 0.000 \\
\hline 1 & 78.7 & 16.4 & 4.9 & \\
\hline 2 & 61.6 & 23.9 & 14.5 & \\
\hline $3+$ & 53.8 & 29.8 & 16.4 & \\
\hline Sex of previous child (children) & & & & 0.074 \\
\hline Male & 63.3 & 23.9 & 12.8 & \\
\hline Female & 69.3 & 20.3 & 10.4 & \\
\hline Ever used contraceptives (couple methods) & & & & \\
\hline
\end{tabular}


Table 1 Bivariate analysis between induced abortions and voluntary family planning dimensions and socio-demographic characteristics (Continued)

\begin{tabular}{lllll}
\hline No & 70.2 & 18.9 & 0.008 & 10.9 \\
\hline Yes & 61.8 & 25.9 & \\
\hline Ever used contraceptives (female methods) & & & 12.3 \\
\hline No & 76.8 & 17.9 & 5.3 & 0.000 \\
\hline Yes & 62.7 & 23.6 & 13.7 \\
\hline
\end{tabular}

Number of living children was significantly associated with a 2.04 fold increase in probability of having an induced abortion. In particular, we found a 3.57 fold increase in probability of having repeated abortions when women already had three or more living children.

Gender of previous child was marginally significant in lowering the odds of ever having induced abortion. Specifically, having previously birthed a daughter resulted in about $28 \%$ lower odds of ever having an induced abortion and 38\% lower odds of having repeated abortions, compared to women who had previously birthed a son (and were more likely to have reached their desired number of children). The rationale of having previously given birth to a daughter (in a country with two-children per couple policy) means the couple has to have another pregnancy that may give them a son. But if a son has already been achieved, then any subsequent pregnancy may or may not be wanted.

Ever-used couple methods was significantly associated with $75 \%$ higher odds of having an induced abortion, but was not significantly associated with increasing the odds of repeated abortions.

Ever-used female methods was significantly associated with $125 \%$ higher odds of having an induced abortion, and also $241 \%$ higher odds of having repeated abortions.

Logistic regression with current contraceptive users only yielded similar results.

Place of residence, wealth index and education were not included in the final logistic regression model. Place of residence and wealth index were significantly associated with number of induced abortions in the bivariate analyses, but these associations were all cancelled and shown to be no longer associated with either one-time induced abortion or repeated abortions when other independent variables were included in the model.

\section{Discussion and policy implications}

Our study results indicate that none of the three VFP dimensions was significantly associated with the odds of having an induced abortion nor repeated abortions. The proportion of women who ever had one abortion and who ever had more than one abortion did not differ significantly among women receiving counseling, information about modern methods, and access to available methods. These findings are not supportive of the mainstream opinion that receipt of VFP services will influence the use of preferred contraceptives and thus will reduce abortion incidence [20]. However, these findings imply that women in general are still receiving poorly performed family planning counseling and inadequate information/communication about their method of choice, not to mention facing limited contraceptive access/availability.

Accessibility affects nonusers of modern methods and current users of traditional methods in Vietnam [8]. When women who preferred to buy contraceptive pills or condoms instead of IUDs did not receive adequate counseling on how to use oral pills nor adequate information about their immediate and long-term side-effects, they did not feel comfortable buying their preferred methods in the open market and thus they continue to use IUD or chose traditional methods. Figure 1 evidences the fact that current use of IUD is still the predominant modern method in Vietnam. In addition, many Vietnamese family planning providers are still holding the same mindset planted by the IUD campaigns in the 1980s. They did not deliver VFP services seriously, and persisted in treating IUD as the method of attention instead of optimizing access to other modern methods. The attitude of family planning providers certainly will affect future VFP counselling and communication strategies. Policy-wise, increasing the availability of modern contraceptive methods other than IUDs, as well as providing quality information, will increase the use of effective modern family planning methods and decrease the use of traditional methods, leading to change the paradoxical situation of high use of contraceptives and high abortion in Viet Nam.

Performing VFP needs more time than the usual 3-5 minutes of provider-client interaction that is typical at the primary care level. A prerequisite of applying additional services such as VFP is a well-motivated workforce, according to a joint-study conducted by researchers from the Hanoi School of Public Health and the Royal Tropical Institute (KIT) in 2003 [21]. It is noteworthy that the data for the Dieleman et al. 2003 study were collected in two provinces adjacent to Thai Nguyen province (where data for our study were collected). This 2003 motivation study was the first of its 
Table 2 Logistic regression on association between voluntary family planning and induced abortion

\begin{tabular}{|c|c|c|c|c|}
\hline & \multicolumn{2}{|c|}{ Ever had one abortion $(n=935)$} & \multicolumn{2}{|c|}{ Ever had repeated abortion $(n=935)$} \\
\hline & OR & $95 \% \mathrm{Cl}$ & OR & $95 \% \mathrm{Cl}$ \\
\hline \multicolumn{5}{|c|}{ VFP dimensions } \\
\hline \multicolumn{5}{|c|}{ Counselling } \\
\hline No & 1 & & 1 & \\
\hline Yes & 0.74 & $0.52-1.06$ & 0.64 & $0.39-1.07$ \\
\hline \multicolumn{5}{|c|}{ Information for informed Choice } \\
\hline No & 1 & & 1 & \\
\hline Yes & 0.97 & $0.67-1.41$ & 0.98 & $0.57-1.67$ \\
\hline \multicolumn{5}{|c|}{ Access/ availability } \\
\hline No & 1 & & 1 & \\
\hline Yes & 0.89 & $0.65-1.20$ & 1.12 & $0.73-1.74$ \\
\hline \multicolumn{5}{|c|}{ Age at interview } \\
\hline $18-24$ & 1 & & 1 & \\
\hline $25-34$ & 2.37 & $1.44-3.90$ & & \\
\hline $35-49$ & 3.99 & $2.35-6.78$ & 2.78 & $1.54-5.03$ \\
\hline \multicolumn{5}{|l|}{ Ethnicity } \\
\hline Others & 1 & & 1 & \\
\hline Kinh & 0.76 & $0.55-1.05$ & 1.18 & $0.72-1.93$ \\
\hline \multicolumn{5}{|l|}{ Occupation } \\
\hline Others & 1 & & 1 & \\
\hline Farmers & 0.57 & $0.41-0.79$ & 0.64 & $0.40-1.02$ \\
\hline \multicolumn{5}{|c|}{ Number of living children } \\
\hline 1 & 1 & & 1 & \\
\hline 2 & 1.32 & $0.87-2.01$ & 2.36 & $1.13-4.95$ \\
\hline $3+$ & 2.04 & $1.16-3.61$ & 3.57 & $1.48-8.57$ \\
\hline \multicolumn{5}{|c|}{ Sex of previous child } \\
\hline Male & 1 & & 1 & \\
\hline Female & 0.72 & $0.54-0.97$ & 0.62 & $0.40-0.95$ \\
\hline \multicolumn{5}{|c|}{ Ever used contraceptives (couple methods) } \\
\hline No & 1 & & 1 & \\
\hline Yes & 1.75 & $1.25-2.46$ & 1.18 & $0.74-1.90$ \\
\hline \multicolumn{5}{|c|}{ Ever used contraceptives (female methods) } \\
\hline No & 1 & & 1 & \\
\hline Yes & 2.25 & $1.45-3.40$ & 3.41 & $1.65-7.08$ \\
\hline
\end{tabular}

kind that looked at rural health workers' perceptions with respect to job motivation at commune and district health centers in rural areas of northern Vietnam [21]. They found that motivation is influenced by both financial and non-financial incentives (such as appreciation by supervisors, colleagues, and the community). Low salaries, difficult working conditions, and lack of communication skills were noted as discouraging factors. Health workers also tend to perceive supervision as control. In addition, selection for training is seen as opaque and unequal, and performance appraisal is not useful [21]. Although the Ministry of Health in Vietnam prioritizes development of a public health network to provide good quality services including family planning, their findings showed that there were still insufficient qualified and motivated human resources in rural areas.

Motivation, or an individual's degree of willingness to exert and maintain an effort to achieve certain organizational goals, is a complex concept. It needs supervision, performance appraisal, career development, and appropriate training. Not all trainings are adequate and casual supervision visits achieve little. Apparently, in-service trainings by vertical health programs (such as the voluntary family planning dimensions) do not count as significant credit points in a health worker's curriculum vitae; in fact, they tend to participate because these 
trainings pay per diems, so they are perceived merely as an income opportunity.

To some extent, the motivational problem found in performing voluntary family planning dimensions is not exclusive to Vietnam. A recent study (2011) that systematically reviews 80 studies from Africa and Asia and the Pacific on quality and performance of private and public ambulatory health care in low- and middle-income countries (published between 1970 and April 2009) concluded that raising the quality of care is a long-term effort. The government has an important role, but supervision, auditing with feedback and quality training have been found to be an effective combination [22].

In order to strenghthen current VFP services in Vietnam, new performance-based measures should be used to record the number of clients counseled and the number of clients given adequate information about IUD and other modern methods. Monitoring of these new measures should be recorded and reported in order to increase the knowledge and availability of all modern methods, not only IUD. Eventually, this will reduce the number of nonusers of pills and condoms and reduce the number of current users of traditional methods. More in-depth training materials about the three VFP dimensions should be incorporated in the pre-service training curricula for students of medicine, midwifery academics, and nurses. The government's women's empowerment program should participate in creating messages that encourage women to obtain information about efficacy of a method before choosing one. This change in orientation should make use of the national standards and guidelines on counselling to protect voluntarism in family planning, and will contribute to the government's efforts to reduce abortion incidence, which will eventually change the paradoxical situation of high use of contraceptives and high abortion in Vietnam.

Our study is limited because it is a cross sectional design; therefore caution must be exercised in the interpretation of the observed associations between induced abortion and VFP measures. In addition, data did not include unmarried women, whose induced abortion behaviors could be different from married women. There was also a possibility that induced abortions among the younger maternal age (18-24) were under-reported because an abortion before the first birth was viewed as disgraceful (implying out-of-wedlock pregnancy). In spite of these limitations, this study is the first one to assess the association between VFP dimensions and induced abortion in Vietnam. Considering that our community-based survey yielded close to a 95\% response rate, and the study sample was a representative sample of married women aged 18-49 years, selected using a two-stage cluster sampling technique, our findings can be generalized to the population of women aged 18-
49 years in Thai Nguyen province and to the wider region of northern Vietnam with the important policy implication for improving family planning services in the country.

\section{Conclusion}

The findings from this study conclude that receiving VFP was not less likely to have induced abortions or repeated abortion services. In other words, there is no relationship between receiving VFP services and the paradoxical situation of high use of contraceptives and induced abortions in Vietnam. Our findings indicated that although the Ministry of Health has initiated the right intervention with VFP trainings for more than 12 years, the provision of family planning counseling, information on contraceptive method mix, and management skills to ensure availability, are still in need of reinforcement. A new set of policy and program strategies in the future (including indepth training on VFP dimensions, new performance-based measures for VFP, monitoring and supportive supervision) needs to reinforce VFP services that can position voluntarism in family planning as a key performance indicator of quality family planning and safe abortion service.

\section{Competing interests}

None of the authors had financial or non-financial competing interests.

\section{Acknowledgements}

The current study is a part of the project that involves collaboration among the Thai Nguyen University of Medicine and Pharmacy, Thai Nguyen

Provincial Health Service, and the Population Council. Research funding was provided through the Population Council Vietnam by the Atlantic

Philanthropies. The authors would like to thank all the participating women (respondents) in this survey for taking the time to share their experiences in interviews; the staff of commune health centers in the four participating districts under the leadership of Dr. Bui Van Hoan, Director of Thai Nguyen Health Department; Professor Dr. Nguyen Van Son, Dr. Nguyen Quang Manh, and other faculty members and students from Thai Nguyen University of Medicine and Pharmacy; Dr Nguyen Truong Nam, Director of the Institute for Social and Medical Studies for his technical support in study design and sampling; Peter Miller, Country Director of Population Council Vietnam for his guidance during the scientific writing training workshop.

\section{Author details}

${ }^{1}$ Department of Scientific Research and International Relationship, Thai Nguyen University of Medicine and Pharmacy, Thai Nguyen, Vietnam. ${ }^{2}$ Department of Biostatistics and Population, University of Indonesia-Faculty of Public Health, Depok, West Java, Indonesia.

\section{Authors' contributions}

PHN participated in concept and design, carried out data collection, and performed the statistical analysis of data and revised manuscript. MPB participated in concept and design, drafted the manuscript and framework of analysis. All authors read and approved the final manuscript.

Received: 1 November 2011 Accepted: 28 May 2012

Published: 28 May 2012

\section{References}

1. PATH and Reproductive Health Department of $\mathrm{MOH}$-Vietnam. Examining the Cost of Providing Medical Abortion in Vietnam: Research Report 2006. 
2. Tuyet $H T$, Thuy $P$, Trang HN: Second trimester abortion in Vietnam: changing to recommended methods and improving service delivery. Reprod Health Matters 2008, 16(31 Suppl):145-150.

3. Do T: More to demand: abortion in Vietnam. Talking Points 2008, 1:6-12.

4. Ertelt S: Vietnam Abortion Rates Very High, One Woman Dies Every Five Days. http://www.lifenews.com/2006/04/03/nat-2184/ 2006.

5. Shears K: Increasing Contraception Reduces Abortion. Network 2002, $21(4) 4-5$.

6. Hoa HT, Toan NV, Johansson A, Hoa VT, Hojer B, Persson LA: Child spacing and two child policy in practice in rural Vietnam: cross sectional survey. BMJ 1996, 313(7065):1113-1116.

7. Nguyen MT, Vu TH: The oral contraceptive pills in Vietnam: situation, client perspectives and possibility for promotion. Asia-Pacific Population Journal 2001, 16(4):31-48.

8. Nguyen MT, Dang NA: Accessibility and Use of Contraceptives in Vietnam. International Family Planning Perspectives 2002, 28(4):214-219.

9. Goodkind D, Phan TA: Reasons for rising condom use in Vietnam. International Family Planning Perspectives 1997, 23(4):173-178.

10. Dang T, Nguyen D: Vietnam Abortion Situations: Country Report. In Conference"Expanding Access: Advancing the Roles of Midlevel Providers in Menstrual Regulation and Elective Abortion Care": 2-6 December 2011; South Africa.

11. Johnston R: Historical abortion statistics, Vietnam. http://www. johnstonsarchive.net/policy/abortion/ab-vietnam.htm/ 2010

12. Goodkind D: Abortion in Vietnam: measurements, puzzles, and concerns. Stud Fam Plann 1994, 25(6 Pt 1)342-352.

13. United Nations Population Division. Abortion Policies: A Global Review. http://www.un.org/esa/population/ publications/abortion/doc/vietnam.doc 2011.

14. WHO: Abortion in Vietnam: an assessment of policy, program and research issues. Geneva: WHO/RHR/HRP/ITT/992; 1999.

15. Pathfinder International Viet Nam: Reproductive Health Projects Report 2011. http://www.pathfind.org/site/PageServer? pagename=Programs_Vietnam_Projects_RHP.

16. Do M, Kurimoto N: Women's empowerment and choice of family planning methods. The University of North Carolina at Chapel Hill, in partnership with Futures Group, Management Sciences for Health and Tulane University: MEASURE Evaluation Working Paper Series WP-10-115; 2010.

17. Vyas $S$, Kumaranayake $L$ : Constructing socio-economic status indices: how to use principal components analysis. Health Policy Plan 2006, 21(6):459-468.

18. Shea OR: The DHS Wealth Index: Approaches for Rural and Urban Areas. Macro International Inc: Demographic and Health Research Division; 2008:60.

19. Gwatkin D, Rutstein S, Johnson K, Suliman E, Wagstaff A, Amouzou A: Socio-economic differences in health, nutrition, and population within developing countries: an overview. Niger J Clin Pract 2007, 10(4):272-282.

20. Eichler R, Seligman B, Beith A, Wright J: Performance-based Incentives: Ensuring Voluntarism in Family Planning Initiatives. Bethesda, MD: Health Systems 20/20 project, Abt Associates Inc; 2010.

21. Dieleman M, Cuong PV, Anh LV, Martineau T: Identifying factors for job motivation of rural health workers in North Viet Nam. Hum Resour Health 2003, 1(1):10.

22. Berendes S, Heywood P, Oliver S, Garner P: Quality of private and public ambulatory health care in low and middle income countries: systematic review of comparative studies. PLoS Med 2011, 8(4):e1000433.

doi:10.1186/1472-6874-12-14

Cite this article as: Nguyen and Budiharsana: Receiving voluntary family planning services has no relationship with the paradoxical situation of high use of contraceptives and abortion in Vietnam: a cross-sectional study. BMC Women's Health 2012 12:14.

\section{Submit your next manuscript to BioMed Central and take full advantage of:}

- Convenient online submission

- Thorough peer review

- No space constraints or color figure charges

- Immediate publication on acceptance

- Inclusion in PubMed, CAS, Scopus and Google Scholar

- Research which is freely available for redistribution

Submit your manuscript at www.biomedcentral.com/submit 